\title{
As implicações sociais da prática de atos infracionais e da privação de liberdade em uma instituição total para adolescentes em conflito com a lei
}

\author{
Social consequences of the practice of criminal offenses and liberty deprivation in an \\ institution dedicated to adolescents in conflict with the law
}

\section{Simone Zanatta Guerra* Giovana Henrich**}

\begin{abstract}
Resumo:
0 presente artigo é resultado da produção do Trabalho de Conclusão do Curso de Serviço Social da Universidade de Passo Fundo intitulado De adolescente a "de menor": as implicações sociais da prática de atos infracionais e da privação de liberdade em uma instituição total para adolescentes em conflito com a lei, construído a partir da experiência do Estágio na área Serviço Social em um Centro de Atendimento Socioeducativo (CASE), onde através de processos de pesquisa analisaram-se quais as implicações do ato infracional e da privação de liberdade para o contexto sócio-familiar dos adolescentes em cumprimento de medida socioeducativa de internação, seguindo quatro eixos norteadores: as vivências dos adolescentes e seu contexto social antes do ingresso ao CASE; as consequências do ato infracional cometido para o adolescente e sua família; a percepção do adolescente a respeito do ato infracional cometido e da medida socioeducativa; e quais as expectativas do adolescente após o cumprimento da medida socioeducativa. Os resultados demonstraram o potencial da instituição e da prática de atos infracionais em modificar percepções e condições concretas de vida, através do estigma, da identificação territorial, da banalização da violência e da expectativa de permanência no mundo do crime.
\end{abstract}

Palavras-chave: Adolescentes em conflito com a lei. Medida socio educativa. Privação de liberdade. Contexto sócio-familiar.

\begin{abstract}
:
The present article is the end result of the Social Work Course, taken in the University of Passo Fundo - RS, conclusion paper entitled "From teen to "minor": Social consequences of the practice of criminal offenses and liberty deprivation in an institution dedicated to adolescents in conflict with the law", built from the social work internship experience in a Socio-Educational Center (CASE in portuguese), where, through research processes, was analyzed the infraction and liberty deprivation implications for the social-family context of adolescents in hospitalization due to social-educational measures based on four guiding axes: previous experiences and their social context before entering the CASE; the consequences of the infraction committed for the adolescent and his family; the teens perception of the infraction committed and the social-educational measures taken; and what are his expectations after fulfilling the social-educational measures. The results showed the institution and the practice of criminal offenses potential to modify perceptions and concrete conditions of life, through stigma, territorial identification, banalization of violence and expectation of permanence in the world of crime.
\end{abstract}

Keywords: Teens in conflict with the law. Social-educative measure. Liberty deprivation. Social and family context.

\footnotetext{
* Assistente Social. Especialista em Ciências Sociais pela Universidade de Passo Fundo - UPF.

** Assistente Social. Doutora em Serviço Social pela Pontifícia Universidade Católica do Rio Grande do Sul PUCRS. Docente do Curso de Serviço Social da Universidade de Passo Fundo - UPF.
} 


\section{Introdução}

Muros altos, grades, portões de ferro e cadeados. Uma unidade da Fundação de Atendimento Socioeducativo do Rio Grande do Sul (FASE/RS), enquanto instituição total ${ }^{1}$, foi o lócus desta pesquisa e de um contínuo movimento de construção e desconstrução de percepções no complexo processo de análise das consequências do ato infracional e da privação de liberdade para adolescentes em conflito com a lei.

Sabe-se que a rede de proteção à infância e juventude no Brasil tem se mostrado falha em responder ao atual contexto de exclusão social no qual crianças e adolescentes estão expostos, como: evasão escolar, trabalho infantil, falta de moradia e alimentação, violência sexual, entre tantas outras violações. Sendo vítimas da violência alguns destes também se tornam autores da crueldade a qual foram submetidos.

Os agora adolescentes em conflito com a lei são privados de sua liberdade em unidades de internação socioeducativa. 0 aprisionamento de jovens - em sua maioria pobres e negros - mostra que há uma "catalogação dos criminosos que combinam com a imagem que corresponde a descrição fabricada." (ZAFFARONI, 2001 apud TEJADAS, 2007, p. 53), em que jovens já excluídos socialmente são detidos.

Deste modo, para expor as percepções tidas ao longo do desenvolvimento desta pesquisa, inicialmente será apresentado o percurso metodológico utilizado. Após, expor-se-á os resultados da pesquisa que serão discutidos a partir de dois eixos: o contexto em que 0 adolescente estava inserido antes da prática do ato infracional e da privação de liberdade e num segundo momento, as consequências para o contexto socio-familiar desse.

Ressalta-se que o objetivo principal é que este trabalho sirva como potencializador de um olhar crítico e sensível frente à adolescência e aos adolescentes em conflito com a lei - e que estes sejam alvo de cuidado, de proteção e principalmente de políticas sociais públicas efetivas.

\footnotetext{
1 'Toda instituição tem tendências de 'fechamento'. Quando resenhamos as diferentes instituições de nossa sociedade ocidental, verificamos que algumas são muito mais 'fechadas' do que outras. Seu 'fechamento' ou seu caráter total é simbolizado pela barreira à relação social com o mundo externo e por proibições à saída que muitas vezes estão incluídas no esquema físico - por exemplo, portas fechadas, paredes altas [...]. A tais estabelecimentos dou o nome de instituições totais" (GOFFM AN, 1961, p. 16).
} 


\section{Caminhos da pesquisa: transformando as inquietações em movimento investigativo}

Inquietar-se. Como não fazê-lo? Há de se naturalizar todas as vivências? Na perspectiva desta escrita crê-se que não, pois a inquietação se torna essência - devaneio primordial na construção de simbologias, percepções e posturas éticas. A inquietação, neste sentido, foi fundamental para compreender de onde os adolescentes vieram e isso, por conseguinte, levou à reflexão sobre as implicações do ato infracional e da privação de liberdade para estes e suas famílias e/ ou comunidades. Desta forma, a curiosidade explícita através de inquietações, mostra a importância da busca pelo conhecimento através da prática investigativa.

Diante disso construiu-se o seguinte problema de pesquisa: Quais são as implicações do ato infracional e da privação de liberdade para o contexto socio-familiar dos jovens em cumprimento de medida socioeducativa de internação no CASE, no período 20132014? Guiados por questões norteadoras, os objetivos ficaram assim delimitados: 1) Geral: Analisar quais são as implicações do ato infracional e da privação de liberdade para o contexto socio-familiar dos adolescentes em cumprimento de medida socioeducativa de internação, visando pensar em alternativas e/ou estratégias de intervir considerando tais aspectos familiares e sociais; e 2) específicos: Investigar as vivências dos adolescentes e seu contexto social antes do ingresso ao Centro de Atendimento Socioeducativo (CASE); estudar as consequências do ato infracional cometido para o adolescente, sua família e à comunidade na qual está inserido; investigar à percepção do adolescente a respeito do ato infracional cometido e da medida socioeducativa em cumprimento; e compreender quais suas expectativas após o cumprimento da medida socioeducativa de privação de liberdade.

No que tange aos aspectos metodológicos a presente pesquisa está conceituada como exploratória, tendo em vista que "pesquisas exploratórias são desenvolvidas com 0 objetivo de proporcionar visão geral, de tipo aproximativo, acerca de determinado fato." (GIL, 1994, p. 45). Já quanto a abordagem da mesma, optou-se pelo viés qualitativo, por se tratar de um tema que contêm múltiplas facetas - e dentre elas algumas que não podem ser quantificadas por dizerem respeito à percepções, vivências, símbolos e ideias. Neste sentido ressalta-se que "a abordagem qualitativa de um problema, além de ser uma opção do investigador, justifica-se, sobretudo, por ser uma forma adequada para entender a natureza de um fenômeno social" (RICHARDSON, 1999, p. 79). 
No que refere aos procedimentos de coleta e as fontes de informação, a pesquisa assumiu caráter documental (com análise do conteúdo dos prontuários dos adolescentes) e de campo, visto que o trabalho de campo é importante para a "[...] aproximação do pesquisador da realidade sobre a qual formulou uma pergunta, mas também estabelecer uma interação com os 'atores' que conformam a realidade e, assim, constrói um conhecimento empírico importantíssimo para quem faz pesquisa social." (M INAYO, 2012, p. $61)$.

Sobre este aspecto é importante de fazer alguns apontamentos. Inicialmente a pesquisa foi planejada como um movimento isolado do restante do processo de estágio. Porém, ao longo deste, percebeu-se que a intervenção e a investigação da realidade em que os sujeitos estavam inseridos eram tão articuladas que não poderiam ser consideradas dois movimentos distintos.

As inquietações que originaram os roteiros previstos para as entrevistas com adolescentes e familiares vinham sendo respondidas em cada encontro entre a estagiária/pesquisadora e os sujeitos da pesquisa (quatro adolescentes e familiares responsáveis por três deles). Assim, através da percepção da indissociabilidade entre a intervenção e a pesquisa, o movimento investigativo foi se dando junto à prática interventiva. Por conta disso, a construção deste trabalho não é só das autoras supramencionadas, mas também dos adolescentes e de suas famílias, a partir de suas visões enquanto sujeitos conhecedores de sua própria realidade e capazes de transformá-la.

Desta forma, seguiu-se o viés da pesquisa-ação que se constitui em "um tipo de pesquisa social que é concebida e realizada em estreita associação com uma ação ou com a resolução de um problema coletivo e no qual os pesquisadores e os participantes "[...] estão envolvidos de modo cooperativo e participativo" (THIOLLENT, 1985, apud BALDISSERA, 2001, p. 5).

Baldissera também refere que a pesquisa-ação "supõe a superação da relação de distanciamento entre o pesquisador, que tem um suporte teórico e metodológico, e as pessoas envolvidas que contribuem com suas experiências, vivências e conhecimentos de sua própria realidade" (BALDISSERA, 2001, p. 9). Por conta disso foi inevitável a vinculação com os sujeitos cujas histórias são apresentadas neste trabalho. Pesquisadores não são imunes ao afeto, tampouco à dor de ouvir os sujeitos em suas angústias, medos e (falta de) expectativas. E como algumas destas escutas foram doloridas. 
Ao longo de todo 0 processo foram muitas falas que fizeram à estagiária/pesquisadora perceber, de modo mais nítido e concreto, a forma como esses sujeitos são massacrados por uma sociedade tão desigual. A forma como são estigmatizados, isolados, criminalizados e culpabilizados. 0 modo como não se sentem integrados pois a exclusão, o descaso, a violência e o abandono foram a maneira com que a sociedade thes tratou. Fatos evidenciados pelos resultados da pesquisa.

\section{Resultados e discussão dos resultados}

Considerando que muitos aspectos surgiram ao longo do processo investigativo e interventivo, e que estes aspectos demonstram a violação que estes adolescentes eram e/ ou são vítimas, desenvolveu-se a análise dos dados e a síntese integradora que seguem a partir de referenciais teóricos e relatos da vida dos quatro adolescentes, que nesta escrita são nomeados ficticiamente de Pedro, Juliano e os irmãos Paulo e Fernando. Assim, num primeiro momento, analisar-se-á as abordagens encontradas sobre o eixo "Vivências do adolescente e contexto sociofamiliar no momento de ingresso no CASE" e após, sobre as abordagens encontradas acerca dos eixos "Consequências do ato infracional", "Percepção sobre 0 ato infracional e a internação socioeducativa" e "Expectativas após o cumprimento da medida socioeducativa".

Contextos de inserção: o não-lugar destinado pela sociedade aos adolescentes em conflito com a lei

Atualmente o Brasil conta com uma ampla legislação a respeito tanto dos direitos humanos de modo geral, quanto da proteção especial à criança e ao adolescente. Tal legislação é responsável pela garantia dos direitos desta parcela populacional. Destaca-se aqui algumas destas leis, a começar pela Constituição Federal de 1988, que afirma serem objetivos fundamentais da República Federativa do Brasil a construção de uma sociedade livre, justa e igualitária; a erradicação da pobreza e da marginalização; a redução das desigualdades sociais; e a promoção do bem de todos, sem distinção e/ou discriminação (BRASIL, 1988, art. 30).

A Constituição prevê ainda que "são direitos sociais a educação, a saúde, a alimentação, o trabalho, a moradia, o lazer, a segurança, a previdência social, a proteção à maternidade e à infância, a assistência aos desamparados" (BRASIL, 1988, art. 6) e que estes - além dos direitos à profissionalização, à cultura, à dignidade e respeito, à liberdade e 
a convivência familiar e comunitária - devem ser assegurados à criança e ao adolescente, com absoluta prioridade, pela corresponsabilização entre família, sociedade e Estado (BRASIL, 1988, art. 227).

Já em 1990 foi promulgado o Estatuto da Criança e do Adolescente (ECA) como legislação complementar que dispõe sobre a proteção integral à criança e ao adolescente (BRASIL, 1990, art. 1o), e que, dentre outras medidas, reafirma os direitos já elencados na Constituição Federal. M as considerando que a sociedade atual segue os ditames do capital e do neoliberalismo, há poucos investimentos do Estado em políticas sociais públicas de qualidade, fragilizando o atendimento às expressões da questão social e, por consequência, limitando a efetivação dos direitos garantidos por estas legislações.

A sociedade por sua vez, segue o caminho do individualismo e da não-empatia com o outro. Isso, associado à falta de recursos pessoais, psíquicos e materiais das famílias destes adolescentes - também vítimas da exclusão social -, foram fatores desencadeadores para a prática do ato infracional por parte destes adolescentes, pois apesar dos direitos preconizados o que se vê são histórias tomadas pela violência e pela violação dos direitos sociais mais básicos.

Neste contexto se faz importante destacar quais são as expressões da questão social vivenciadas por estes adolescentes. Destaca-se algumas delas como de maior visibilidade: violência, fragilização dos vínculos familiares, drogadição, não-acesso às políticas sociais públicas, baixa escolaridade e analfabetismo.

Os resultados da pesquisa mostram que, em geral, os adolescentes em cumprimento de medida socioeducativa vêm de um contexto de vulnerabilidade social e econômica e de violação de direitos sociais básicos. Neste sentido, Feijó e Assis (2004) associam o problema da prática de atos infracionais ao contexto de exclusão e de vulnerabilidade social que estes estavam inseridos. Exclusão esta que pode ser, segundo os autores, "[...]econômica, social, cultural, territorial e étnica, fazendo com que através da falta de oportunidades para o indivíduo e sua família, o sentido da sua vida e existência seja afetado, bem como suas expectativas para o futuro." (FEIJÓ; ASSIS, 2004, p. 158).

Percebe-se assim que as histórias trazidas pelos adolescentes sujeitos da pesquisa são retratos que se repetem. São mais três famílias postas à margem da sociedade, morando em áreas periféricas sem acesso à educação, à saúde e a assistência social. Três famílias que 
não foram olhadas, não foram vistas, não foram ouvidas, como observável nos relatos a seguir².

Eu conheci o local onde Pedro nasceu e cresceu. Um beco em um bairro de extrema vulnerabilidade social. Sem dúvida um ambiente comunitário e social de risco. Ele fazia referência a uma "boca de fumo" que ficava em frente à sua casa.

0 motivo da mudança (da família de Juliano) foi buscar melhores condições de vida, especialmente no que tange à saúde de Paula, que foi diagnosticada com depressão e um tumor maligno no cérebro. Assim, pensavam que vindo para uma cidade maior, poderiam ser mais bem atendidos nessas demandas - fato que já demonstra uma falha das políticas públicas. [...] Passaram a residir em uma área irregular, sem infraestrutura de saneamento básico. Juliano desistiu de estudar - e já havia sido expulso da escola no outro município em que residia.

(Paulo e Fernando) Passaram a residir então em uma área de elevado risco social, com altos índices de violência e de tráfico de drogas. Nesse contexto, os adolescentes passaram a fazer uso de maconha e evadiram da escola, não tendo sido alfabetizados.

Estes adolescentes, bem como suas famílias, foram destinados a um não-lugar. 0 direito a cidade, caracterizado pelo acesso igualitário a ela, considerando o espaço urbano enquanto lócus de efetivação da cidadania, não Ihes foi garantido.

O Estatuto da Cidade reafirma o direito "[...] a cidades sustentáveis, entendido como o direito a terra urbana, a moradia, ao saneamento ambiental, a infraestrutura urbana, ao transporte e aos serviços públicos, ao trabalho e ao lazer, para as presentes e futuras gerações" (BRASIL, 2001, Art. 1) e a "justa distribuição dos benefícios e ônus decorrentes do processo de urbanização" (BRASIL, 2001). Todavia, o que se verifica no cotidiano é o inverso do previsto por tal legislação. E isto não aconteceu só com essas famílias, mas sim com essas e tantas outras que se viram "trancados do lado de fora" a partir do momento em que, ao não acessar os serviços públicos existentes, passam também a não se sentirem parte daquela cidade e/ ou espaço.

Neste sentido, embora cada adolescente tenha suas particularidades, todos vieram de um contexto de extrema vulnerabilidade e ao serem vítimas da violência multifacetada também se tornam autores desta, como resposta ao lugar que a sociedade lhe destina e como forma de reagir à invisibilidade que the é imposta. 0 ato infracional funciona, neste sentido, é como um grito de socorro à sociedade e em especial às políticas públicas: "Ei, eu existo. Eu estou aqui!" - buscando o reconhecimento numa "perspectiva destrutiva, sem dúvida, mas que se evidencia nas trajetórias dos adolescentes" (TEJADAS, 2007, p. 218). Petracco $(2007$, p. 5) também analisa a questão através deste viés com a percepção de que,

\footnotetext{
${ }^{2}$ Relatos retirados do Trabalho de Conclusão de Curso que deu origem a este artigo.
} 
[...] em muitos casos, a infração funciona como pedido de ajuda, um grito por socorro. Na medida em que as necessidades e fragilidades não puderam contar com 0 acolhimento familiar e social, apela-se a autoridade judiciária. Não é por acaso que muitos adolescentes que se envolvem com o tráfico de drogas acabam tendo no patrão da boca, como é por eles chamado o chefe desta rede, uma referência do mundo adulto (PETRACCO, 2007, p. 5).

Percebe-se assim que, no contexto de vida dos adolescentes cujas histórias aqui são brevemente apresentadas, ocorreram falhas da rede socioassistencial de proteção à criança e ao adolescente. Muitos socioeducandos não tiveram acesso digno às políticas sociais públicas antes de ingressarem na unidade de socioeducação. Há altos níveis de defasagem escolar, salvo raríssimos casos em que os adolescentes internados na unidade não estão na série correspondente às suas idades, e muitos apresentam grandes dificuldade para ler e escrever.

Dos quatro adolescentes sujeitos da pesquisa, todos se encontravam afastados da escola antes do ingresso ao CASE. Destes, dois foram expulsos desta sem o devido acompanhamento da política de educação. Foram jogados à mercê da própria sorte por quem devia, pela corresponsabilidade do Estado face à criança e ao adolescente, protegêlos. Os outros dois, irmãos, analfabetos aos 16 e 17 anos de idade, fizeram referência à dois motivos para terem evadido da escola: o estigma e a violência doméstica.

O uso e abuso de substâncias psicoativas (SPAs) também é um problema relacionado à violência juvenil. Neste sentido, estudos relacionam o uso e dependência de drogas com a prática de atos infracionais. De acordo com Rocha (2002, p. 129), "[...] há uma comprovada prevalência do uso de drogas entre os adolescentes em conflito com a lei, fazendo-se necessário a criação de políticas públicas que deem resposta a tal demanda social."

Sobre este aspecto, há ainda que se compreender que são múltiplas as dependências relacionadas às SPAs, que acabam por motivar seu uso. Neste sentido destaca-se a dependência dos efeitos, especialmente o prazer e a fuga da realidade; a dependência dos pares, buscando o sentimento de pertencimento a um grupo; e a dependência das crenças, através das representações sociais em torno da droga e de seus efeitos (PEREIRA; SUDBRACK, 2008).

Ressalta-se ainda que, no decorrer no processo de pesquisa-ação, também percebeu-se que grande parte dos adolescentes em privação de liberdade no CASE eram usuários de SPAs - e que, em alguns casos, o cometimento do ato infracional tinha estreita 
relação com 0 abuso de drogas, à exemplo da realização de roubos e/ou furtos para conseguir dinheiro para comprá-las ou de atos infracionais cometidos sob efeito de SPAs. Porém, faz-se necessária uma reflexão crítica sobre tal temática para que não haja a vinculação mecânica entre consumo de SPAs e periculosidade e/ou criminalidade, a fim de não criminalizar o sujeito em uso de tais substâncias, fato este que gera estigmatização e dificulta 0 acesso aos serviços públicos de saúde.

Também é relevante analisar a fragilização dos vínculos familiares. Percebida nas falas e histórias de vida dos adolescentes internos no CASE, compreende-se tal expressão da questão social como motivadora e/ou facilitadora no cometimento de atos infracionais. No referente a Fernando,

[...] percebe-se que há um distanciamento dele com a mãe. Fernando refere que esta não vem visitá-lo "porque tá me castigando, por que eu não morava com ela". [...] (A mãe) relata não ter a intenção de acolher o filho após seu desligamento da Unidade, argumentando que ele prefere morar com o pai e os irmãos.

Ao ouvi-lo, foi perceptível a falta de acolhimento familiar. Ressalta-se neste sentido que embora 0 adolescente tenha vínculo fortalecido com o pai e os irmãos mais velhos, essas figuras masculinas Ihe são apresentadas através de uma representação social de poder relacionado ao tráfico de drogas - e, desta forma, suas referências no mundo adulto acabam voltadas à violência e à criminalidade.

Sobre isso, Junqueira e Jacoby (2006) destacam alguns fatores de risco para 0 cometimento de atos infracionais associados ao ambiente familiar, dentre eles: falta de supervisão e exercício da autoridade por parte dos responsáveis pelo adolescente; ausência de recursos e políticas adequadas para 0 atendimento da criança e do adolescente na ausência dos responsáveis; ausência do papel paterno e/ou materno estabelecido; e histórico infracional e de institucionalização na família do adolescente. E são por estes motivos, verificados empírica e bibliograficamente, que às visões idealizadas de família, enquanto proteção, afeto e cuidado, devem ser desconstruídas.

Referente à tal dimensão, Martins et al. (2007, p. 5) afirmam que,

[...] desde a Antiguidade e, sobretudo, na atualidade, a família representa o espaço prioritário e o alicerce onde se estabelecem as oportunidades de so cialização, bemestar e proteção nas relações humanas. As características de cada núcleo familiar, sua constituição, condições e qualidade de vida a que está submetido impõe a esse núcleo um maior ou menor grau de vulnerabilidade e, consequentemente, maior ou menor grau de empoderamento. A realidade da vida moderna nos impõe um conjunto de fatores de ordem moral, social, econômica, política e cultural que 
concorrem para que a família e a sociedade se organizem, muitas vezes, desrespeitando os princípios e valores fundamentais da vida e da convivência humana. A família configura-se, assim, como espaço que reproduz cotidianamente o poder de hierarquia e subordinação do do minante sobre o do minado, do domínio de adultos sobre crianças.

Desta forma, também estando expostas às vulnerabilidades sociais, as famílias por vezes não estão orientadas a partir do pressuposto da proteção, mas sim de uma reprodução da realidade de pobreza material e simbólica a que estão inseridas. Por conta disso, a família,

[...] pode ou não se mostrar capaz de desempenhar suas funções básicas. 0 importante é notar que esta capacidade resulta não de uma forma ideal e sim de sua relação com a sociedade, sua organização interna, seu universo de valores [...]. Em consequência, qualquer forma de atenção e/ou de intervenção no grupo familiar precisa levar em conta sua singularidade, sua vulnerabilidade no contexto social, além de seus recursos simbólicos e afetivos (BRASIL, 2004, p. 36).

Assim, as famílias destes adolescentes se encontravam à margem - física e simbólica -, em locais afastados do centro da cidade e dos equipamentos sociais que deveriam incluí-las. Em uma área ocupada irregularmente ou em um pequeno beco num bairro vulnerável. Lá elas estavam o tempo todo e lá não tiveram acesso às políticas sociais públicas. As redes socioassistenciais só conheceram os adolescentes após seu envolvimento em atos infracionais. Esta é a tradução da face mais cruel do neoliberalismo: vidas que se tornaram números, códigos, infrações.

São histórias observadas, muitas vezes, de apenas um ponto de vista: é "de menor" - e de tal modo o adolescente acaba vendo, como num processo de evaporação, suas posições enquanto sujeito em condição peculiar de desenvolvimento e portador de direitos serem anuladas por uma lógica de culpabilização e de individualização da questão social.

E o depois? As implicações sociais da prática de atos infracionais e da privação de liberdade

Juliano demonstrou, ao longo da internação, bem como em nossas conversas, por conta da intervenção e da pesquisa, que se sente estigmatizado e que internalizou tal estigma. Assim, para além da área de Como exposto acima, estes sujeitos vêm de territórios e/ou contextos de extrema vulnerabilidade social. Mas, para além disso, há implicações sociais que decorrem da prática do ato infracional e da privação de liberdade em uma 
instituição total para adolescentes em conflito com a lei. Sendo o desvelamento destas consequências o principal objetivo do presente texto, questionou-se e buscou-se aqui responder - todavia, não objetivando esgotá-las, visto suas múltiplas expressões: quais são estas implicações?

Um primeiro aspecto que merece destaque diz respeito ao estigma que passa a ser associado à estes adolescentes e suas famílias - tendo em vista que numa perspectiva psicossocial "o processo de estigmatização se refere à desvalorização, perda de status e consequente discriminação de um indivíduo desencadeada pela atribuição de estereótipos negativos com base em características físicas e pessoais [...] consideradas socialmente inaceitáveis." (LINK; PHELAN, 2001; CORRIGAN; WATSON, 2002 apud FELICISSIMO et al., 2013, p. 117).

Neste sentido deve-se observar que há criminalização da pobreza e das expressões da questão social e considerar que, em grande maioria, os adolescentes internos em unidades de socioeducação, como já sinalizado, vieram de comunidades carentes. Este fato, somado ao cometimento de atos infracionais, gera 0 isolamento desses indivíduos bem como marcas permanentes em sua constituição física, psíquica, familiar, comunitária e social - a certidão de antecedentes criminais pode estar vazia, mas a sociedade ainda estará recheada de preconceitos e atos discriminatórios contra eles.

Destarte, segundo Caldeira (2000, p. 27), "[...] a fala do crime - ou seja, todos os tipos de conversas, comentários, narrativas, piadas, debates e brincadeiras que têm o crime e o medo como tema - é contagiante" e ela "tampouco incorpora experiências dos grupos dominados (os pobres, os nordestinos, as mulheres etc.); ao contrário, ela normalmente os discrimina e criminaliza" (CALDEIRA, 2000, p. 43). Esta fala produtora de segregação social e espacial, contesta os direitos da cidadania (CALDEIRA, 2000).

Partindo de tais aspectos, observa-se que o processo de estigmatização gera ainda uma consequência extremamente negativa para suas vítimas: a internalização de tal estigma, que "[...] ocorre na medida em que o indivíduo em condição estigmatizante tornase consciente dos estereótipos negativos sobre seu transtorno, concorda com eles e os aplica a si próprio." (CORRIGAN; WATSON, 2002 apud SOARES et al., 2011, p. 636). Isso pode ser observado nos relatos de vida dos sujeitos da pesquisa, especialmente nas histórias de Juliano e dos irmãos Fernando e Paulo. 
Risco social onde reside com sua família, também tem vergonha dos vizinhos pelo envolvimento no ato infracional. Tal sentimento também é percebido no discurso de Paula (mãe de Juliano), ao dizer que "não me sinto bem aqui, nem ele. Parece que as pessoas ficam olhando pra nós".

Fernando relata que, desde novo, brigava na escola por que estigmatizavam seus irmãos, especialmente o mais velho - que chamarei aqui de Felipe. [...] Argumenta que foi esse o motivo que o fez evadir da escola. Fabiana (mãe) também diz que já escondeu 0 fato de ser mãe de Felipe, temendo ser criticada e/ou perder 0 emprego. Ela ainda me relatou que no momento em que alugou uma casa para viver com seu atual companheiro e enteada, "os vizinhos ficaram sabendo que eu era mãe do Felipe e viam os meninos irem ali em casa, e aí procuraram a dona da casa para reclamar". Assim, ela disse que sofre muito com o preconceito e que "minha sogra, até hoje, não me aceita". Neste sentido, ela refere estar fazendo uso de psicotrópicos, pois sente-se "mal" tendo quatro filhos institucionalizados ${ }^{3}$.

Por serem estigmatizados isso acaba gerando a internalização do estigma, o que pode causar perda de identidade, restrição das oportunidades de vida, diminuição da autoestima, sentimento de vergonha, culpa, raiva e isolamento (FELICISSIMO et al., 2013; SOARES et al., 2011). No âmbito exclusão-inclusão o estigma e sua internalização funcionam como mecanismos de exclusão que, implícita ou explicitamente, reforçam a negação do acesso dessa parcela populacional a seus direitose, por fim, a qualidade de vida.

Também se percebe nitidamente que a violência se configura num movimento circular. Ela "[...] existe num determinado contexto e se efetiva na relação com o outro [...], enquanto fenômeno multifacetado que assume formas e sentidos variados, em acordo com o momento histórico e a cultura em que ele é produzido." (GUIM ARÃES; CAM POS, 2007, p. 189).

A vida destes adolescentes foi marcada por essa violência em suas mais variadas formas - a violência familiar, a carência de afeto, a violência econômica, 0 não acesso às políticas sociais públicas, o preconceito e a segregação racial e/ou social. Foram vítimas da violência do capitalismo predatório e, por conseguinte, reproduziram-na.

Através da percepção de que suas vidas não tinham, à sociedade, 0 mesmo valor dado as demais, responderam à sua maneira. Com exceção do adolescente Juliano, os demais parecem banalizar em seus discursos a violência quanto a vida. Trata-se assim de uma resposta violenta à um contexto violento e vulnerável - o capitalismo e as relações societárias violaram seus direitos e, na carência de recursos materiais, psíquicos e sociais, eles viram na violência uma forma de enfrentamento de suas realidades e de busca por reconhecimento e visibilidade.

\footnotetext{
${ }^{3}$ Dois irmãos dos adolescentes também estavam no presídio no momento de produção deste trabalho.
} 
Tal banalização influi na percepção do adolescente a respeito do ato infracional cometido. A exceção parece ser 0 adolescente Juliano, que demonstra compreender a gravidade do ato infracional cometido e em seu discurso vê para si perspectivas de vida diferentes. Ele refere que 0 ato infracional "foi errado, né, tô por sair daqui e não fazer mais. Sair daqui e estudar, trabalhar". Sobre este aspecto, ressalta-se a importância da resiliência, tanto no processo de responsabilização quanto na construção de novos projetos de vida.

A resiliência traduz-se em um "processo marcado pela dinamicidade, pela interação de diversas condicionalidades que possibilitam a superação de adversidades" (TOLEDO, 2010, p. 58). Nesse sentido ela é "fruto de um processo de interação entre o sujeito e os fatores de proteção disponíveis a ele, interação esta que o fortalece e o capacita para transpor as adversidades da vida." (TOLEDO, 2010, p. 59).

No caso de Juliano os vínculos familiares fortalecidos se constituíram em um destes fatores de proteção. Ressalta-se, todavia, que "não há que se falar em pessoas resilientes e não-resilientes, considerando que todos os sujeitos possuem, em diferentes graus, o potencial de resiliência, que dependendo das condicionalidades dos fatores de proteção pode se desenvolver de diferentes formas" (ASSIS, 2006 apud TOLEDO, 2010, p. 59).

Os demais adolescentes - Pedro, Fernando e Paulo -, associam os atos infracionais cometidos a circunstâncias de violência, banalizando-a. Segundo Guimarães e Campos (2007, p. 189),

[...] com a atual mudança cultural e as transformações do sistema de valores e das relações sociais, observa-se que as tensões sociais que anteriormente apresentavam desfechos onde tendiam a predominar acordos e negociações, atualmente encontram na violência física ou verbal uma tendência predominante. Nota-se assim uma disposição cultural de se considerar fenômenos de violência explícita (atos agressivos) como sendo, além de frequentes, "comuns", "naturais", "corriqueiros", "banais", destituindo a violência do lugar da excepcionalidade, para tornar-se uma marca do cotidiano. [...] (Ocorre) a legitimação do uso da agressão (física ou simbólica) como forma de regulação/resolução de conflitos de interesses, seja entre pessoas ou grupos.

É neste sentido que Pedro justifica o homicídio cometido por conta de uma briga envolvendo o consumo de SPAs, não mostrando uma responsabilização efetiva pelo ocorrido. Já Fernando e Paulo estão visivelmente embrenhados no mundo e/ou nas vivências do tráfico de drogas - seja pela invisibilidade social, pela busca por reconhecimento e uma identidade social própria ou pelo "pseudo status" de poder (MEIRELLES; GOM EZ, 2009). 
Os adolescentes naturalizaram a tal ponto as regras sociais deste contexto que não denotam responsabilização pelos atos infracionais de homicídio e tentativa de homicídio, que respondem concomitantemente a privação de liberdade por tráfico de drogas. Justificam tais atos dizendo que "é a lei do tráfico". É relevante relembrar que os adolescentes cresceram neste contexto de violência e desde crianças se viram envolvidos nestas sensações trazidas pelo tráfico - sobre isso, ressalta-se que em nenhum momento do processo de pesquisa-ação os irmãos trouxeram boas lembranças de suas infâncias, somente recordações envolvendo a violência doméstica, o uso de drogas e o histórico infracional na família.

Destaca-se ainda que os relatos dos adolescentes também apontam uma perspectiva de vida ligada à perpetuação da violência, através da prática de novos atos infracionais e/ou crimes após completarem a maioridade penal. Assim, Pedro projeta a realização de novos atos infracionais, vendo a prática de agressões como a melhor forma de resolução de seus conflitos.

Ressalta-se que este aspecto da perpetuação da violência está intrinsicamente ligado, nos casos pesquisados, ao território de origem dos sujeitos, que são espaços de exclusão e de abandono das políticas sociais públicas, visto que:

[...] a produção de "refugo humano", ou, mais propriamente, de seres humanos refugados (os "excessivos" e "redundantes", ou seja, os que não puderam ou não quiseram ser reconhecidos ou obter permissão para ficar), é um produto inevitável da modernização [...]. É um inescapável efeito colateral da construção da ordem (cada ordem define algumas parcelas da população como "deslocadas", "inaptas" ou "indesejáveis") e do progresso econômico [...] (BAUM AN, 2005, p. 12).

Eles, vistos como excessivos, são deixados à mercê de condições subumanas de vida isolados em territórios de risco. Pode-se observar a influência do território na prática infracional e na construção de expectativas para o futuro. Também se percebe como tanto a prática quanto a privação de liberdade em uma instituição total para adolescentes em conflito com a lei geram implicações na construção de projetos de vida.

As implicações negativas se referem à falta de expectativas de vida - ou, ao menos, de expectativas de uma vida com vínculos familiares fortalecidos e longe do mundo do crime. Esta falta de expectativas está explícita no discurso da mãe de Fernando e Paulo, ao dizer que "não posso esperar muita coisa, deles saírem e fazer o bem deles, porque não sei se eles têm essa vontade". 
Por conta disso e tendo em vista que, segundo Tejadas (2007, p. 18), "[...] sem encontrarem espaços de acolhimento, de identificação, de construção de perspectivas de vida orientadas por projetos socialmente aceitos, muitos jovens iniciam trajetórias de envolvimento com o crime", ao serem vistos como sujeitos sem possibilidade de ter novas e diferentes perspectivas de vida - através de um viés determinista de que a prática do ato infracional já definiu seu futuro como ligado ao crime e seu caráter como de criminoso sem possibilidade de "recuperação" - há a tendência de perpetuação do crime, através do não reconhecimento da cidadania destes sujeitos, ainda na sua adolescência.

Assim não thes são dadas as oportunidades necessárias para a construção de perspectivas de vida diferentes e desta forma, os projetos de vida destes adolescentes estão associados a violência e a perpetuação desta, seja como autor, seja como vítima. Isso porque no relato dos quatro adolescentes e/ ou de seus familiares, o medo e a insegurança referente ao futuro se fizeram presentes. Tais sujeitos referiram que os quatro adolescentes já sofreram ameaças associadas a tais contextos violentos.

Outro aspecto que surgiu ao longo do processo de pesquisa-ação se refere ao aprisionamento dos sujeitos e/ou ao sentir-se confinado, tendo em vista a institucionalização destes adolescentes, na medida em que a internação em uma instituição total,

[...] representa ele a supressão da intimidade, da individualidade e das características individuais do jovem, introduzindo-o em um meio em que ele nunca será sujeito e onde todas as dimensões de sua vida passarão a ser encaradas so b o enfoque do que é mais conveniente para a instituição, em termos da observância de suas regras funcionais e disciplinares (SILVA, 1999, apud IFANGER, 2011, p. 44).

Assim, ao se verem confinados no CASE - local com características de uma instituição total - dão vazão a outros sentimentos, conforme percebido ao longo do processo de pesquisa-ação. Há entre eles o distanciamento do próximo, tendo em vista as barreiras impostas à relação e/ou ao contato com o mundo exterior, a exemplo da mãe de Juliano, que faz referência à falta que seu filho the faz; e também as implicações na saúde mental dos sujeitos, na medida em que a psique também se mostra afetada com tal confinamento, levando inclusive a ideação suicida.

Por fim, a partir do exposto, conclui-se que há, indubitavelmente, uma questão transversal que perpassa todos os aspectos que foram apresentados nesta síntese integradora: a questão identitária. A identidade destes sujeitos - o self adolescente - 
também foi sendo alterada na medida em que eles praticaram a infração e foram aprisionados em uma unidade de socioeducação, especialmente porque, segundo Carvalho, a adolescência constitui-se em "uma etapa que impele o indivíduo a uma redefinição da própria identidade" (1996 apud OLIVEIRA, 2006, p. 428).

$\mathrm{Na}$ medida em que se compreende que "o contexto cultural tem o papel de regular as condições sociais de constituição do senso de si" (OLIVEIRA, 2006, p. 430) e sendo a identidade também uma construção social ${ }^{4}$, não se pode negar à influência de uma instituição total, como o CASE, em modificá-la. E estas transformações, em foco nos casos de culpabilização, estigma e aprisionamento, não poderão ser positivas. Por conta disso, é necessário - e de extrema urgência - repensar não só a primazia da internação $0^{5}$ frente a outras medidas socioeducativas, mas também 0 investimento em políticas sociais públicas que possibilitem a vivência de infâncias e adolescências sadias às crianças e adolescentes, com acesso à educação, saúde, lazer, cultura e demais direitos sociais previstos em lei. Só assim poder-se-á desfazer os ciclos de violência e construir ciclos de vida.

\section{Considerações finais}

M uitas são as problematizações que devem ser feitas em relação aos adolescentes em conflito com a lei e o discurso societário sobre eles, ainda muito estreito e repleto de estigmas. Para tanto, é preciso alargar as margens destes discursos, abrir caminhos, desfazer preconceitos e pré-conceitos. É necessário olhar para além do ato infracional propriamente dito e refletir sobre a sociedade, a forma como esta se organiza e, de igual forma, como exclui uma grande parcela populacional criminalizando-a e isolando-a em espaços periféricos.

Assim, o presente trabalho, no ímpeto de responder a estas inquietações, oportunizou às autoras andar sobre a areia movediça. Neste processo pôde-se compreender melhor o movimento dialético entre a violência societária e a violência de que fazem uso os adolescentes em conflito com a lei, tendo como lócus de atuação a contradição da sociedade contemporânea.

\footnotetext{
${ }^{4}$ Segundo Tejadas (2007, p. 67), "[...] o 'eu' expresso na identidade subjetiva [...] se dará no processo social, devendo ser compreendido a partir do contexto social particular em que se gerou."

${ }^{5}$ Apesar de na legislação a internação ser apontada como a última medida a ser aplicada ao adolescente em conflito com a lei, percebeu-se que, na prática, alguns magistrados não a usam apenas em casos excepcionais, para os quais seria indicada, mas também para situações em que seria mais adequada a aplicação de uma medida socioeducativa em meio aberto, onde o protagonismo juvenil e a construção de outros projetos de vida poderiam ser potencializados.
} 
Antes de encerrar é necessário fazer mais algumas assinalações. A primeira delas é que, embora ainda haja muitas limitações no atendimento aos adolescentes em conflito com a lei, em muitos aspectos houve avanços bastante significativos, como a promulgação do Estatuto da Criança e do Adolescente (ECA), fundado sob a doutrina de proteção integral à tais sujeitos, e da Lei do Sistema Nacional de Atendimento Socioeducativo (SINASE), que estabelece diretrizes para 0 atendimento em socio-educacional.

0 que ainda carece é o respeito integral a tais legislações através de um Estado e uma sociedade que de fato efetive os direitos sociais garantidos por lei, pois somente assim será possível garantir a construção de novos projetos de vida às crianças e adolescentes brasileiros.

Um segundo aspecto relevante é a questão do encarceramento juvenil. $\mathrm{Na}$ sociedade contemporânea, prevalece 0 discurso de impunidade ao adolescente autor de ato infracional, potencializador de movimentos pela redução da maioridade penal. Não se percebe, todavia, que o mero encarceramento em uma instituição total - seja de socioeducação ou prisional - não é capaz de gerar uma real responsabilização do adolescente pelo ato infracional, bem como não tem se mostrado o melhor caminho, pois, em geral, o que se vê é um movimento de mera repressão e isolamento, culpabilizando unicamente o adolescente pelo ocorrido. Tem-se a visão de que 0 aprisionamento ressocializa e reintegra, quando, muitas vezes, o efeito é o contrário pois, como apareceu nos resultados da pesquisa, pode haver a potencialização da violência e de sua banalização. Denota-se, nesse sentido, que a internação deve ser a última medida a ser utilizada pelos magistrados, pelos próprios riscos sociais inerentes a ela - e de acordo com o ECA.

E, por fim, um último aspecto a ser ressaltado: 0 ato infracional não pode ser visto de forma isolada, pois é reflexo de um contexto societário muito mais amplo. Não se pode dissociá-lo da realidade social do adolescente que o praticou, sob o risco de tão meramente culpabilizá-lo e, assim, favorecer à perpetuação da violência através da falta de perspectivas de vida. Não se prega aqui, todavia, a desresponsabilização do adolescente, mas sim que esta responsabilização se dê associada a mudanças nas relações sociais e nas condições concretas de vida dele e de sua família, através da garantia dos direitos sociais e, deste modo, potencializando a construção de novos projetos de vida longe do "mundo do crime".

Ressalta-se que não buscou esgotar a análise de tal temática, mas sim inquietar seus leitores a fim de impulsionar um movimento reflexivo acerca dos elementos aqui trazidos e de suas implicações sociais, para que, quem sabe um dia, as redes de proteção à 
criança e ao adolescente sejam fortalecidas e haja novas alternativas aos adolescentes autores de atos infracionais.

\section{Referências}

BALDISSERA, A. Pesquisa-ação: uma metodologia do "conhecer" e do "agir" coletivo. Revista Sociedade em Debate, Pelotas, v. 7, n. 2, p. 5-25, ago. 2001. Disponível em: http://revistas.ucpel.tche.br/index.php/rsd/article/view/570. Acesso em: 1 out. 2014.

BAUM AN, Z. Vidas desperdiçadas. Tradução de Carlos Alberto Medeiros. Rio de Janeiro: Jorge Zahar Ed., 2005.

BRASIL. [Constituição (1988)]. Constituição da República Federativa do Brasil. Disponível em: http://www.planalto.gov.br/ccivil_03/Constituicao/Constituicao.htm. Acesso em: 1 out. 2018.

BRASIL. Lei no 10.257, de 10 de julho de 2001. Regulamenta os Artigos 182 e 183 da Constituição Federal, estabelece diretrizes gerais da política urbana e dá outras providências. Brasília: Presidência da República, 2001. Disponível em:

http://www.planalto.gov.br/ccivil_03/LEIS/LEIS_2001/L10257.htm. Acesso em: 5 maio 2018.

BRASIL. Lei no 8.069, de 13 de julho de 1990. Dispõe sobre o Estatuto da Criança e do Adolescente e dá outras providências. Brasília: Presidência da República, 1990. Disponível em: http://www.planalto.gov.br/ccivil_03/leis/L8069.htm. Acesso em: 5 maio 2018.

BRASIL. Política nacional de assistência social. Brasília: M inistério do Desenvolvimento Social e Combate à Fome, 2004.

CALDEIRA, T. Cidade de muros: crime, segregação e cidadania em São Paulo. São Paulo: Edusp, 2000.

FEIJÓ, M.; ASSIS, S. O contexto de exclusão social e de vulnerabilidades de jovens infratores e de suas famílias. Revista Estudos de Psicologia, Natal, v. 9, n. 1, 2004. Disponível em: www.scielo.br/pdf/epsic/v9n1/22391.pdf. Acesso em: 11 ago. 2014.

FELICISSIM O, F.; FERRIERA, G.; SOARES, R.; SILVEIRA, P.; RONZANI, T. Estigma internalizado e autoestima: uma revisão sistemática da literatura. Revista Psicologia: teoria e prática, São Paulo, v. 15, n. 1, p. 116-129, jan./abr. 2013. Disponível em:

http://pepsic.bvsalud.org/pdf/ptp/v15n1/10.pdf. Acesso em: 22 set. 2014.

GIL, A. M étodos e técnicas de pesquisa social. 4. ed. São Paulo: Editora Atlas, 1994.

GOFFM AN, E. Manicômios, prisões e conventos. São Paulo: Editora Perspectiva, 1961.

GUIM ARÃES, S.; CAM POS, P. Norma Social violenta: um estudo da representação social da violência em adolescentes. Psicologia: reflexão e crítica, Porto Alegre, v. 20, n. 2, 2007. 
IFANGER, F. Considerações críticas acerca da medida socio educativa de internação. Boletim da Escola da Defensoria Pública, São Paulo, n. 3, p. 44-46, jul./dez. 2011. Disponível em: http://www.defensoria.sp.gov.br/dpesp/repositorio/20/Boletim_EDEPE\%2027.07.11.pdf\#pa ge $=44$. Acesso em: 16 out. 2014.

JUNQUEIRA, M.; JACOBY, M. O olhar dos adolescentes em conflito com a lei sobre 0 contexto social. Revista Virtual Textos \& Contextos, Porto Alegre, n. 6, dez. 2006. Disponível em: www.revistasel etronicas. pucrs.br/ojs/index.php/fass/article/viewFile/1036/815. Acesso em: 16 set. 2013.

MARTINS, C.; FERRIANI, M .; SILVA, M .; ZAHR, N.; ARONE, K.; ROQUE, E. A dinâmica familiar na visão de pais e filhos envolvidos na violência doméstica contra crianças e adolescentes. Revista Latino-Americana de Enfermagem, Ribeirão Preto, v. 15, n. 5, set./ out. 2007. Disponível em: http://www.scielo.br/pdf/rlae/v15n5/pt_v15n5a01.pdf. Acesso em: 10 out. 2014.

MEIRELLES, Z; ; GOMEZ, C. Rompendo com a criminalidade: saída de jovens do tráfico de drogas em favelas na cidade do Rio de Janeiro. Revista Ciência \& Saúde Coletiva, Rio de Janeiro, v. 14, n. 5, p. 1797-1805, 2009. Disponível em: বhttp:// www.scielo.br/pdf/csc/v14n5/21.pdf>. Acesso em 25 set. 2014.

MINAYO, M. (org). Pesquisa social: teoria, méto do e criatividade. 31. ed. Petrópolis: Editora Vozes, 2012.

OLIVEIRA, M. Identidade, narrativa e desenvolvimento na adolescência: uma revisão crítica. Revista Psicologia em Estudo, M aringá, v. 11, n. 2, maio/ago. 2006. Disponível em: $\varangle w$ ww.scielo.br/pdf/pe/v11n2/v11n2a21.pdf>. Acesso em: 11 ago. 2014.

PEREIRA, S.; SUDBRACK, M. Drogadição e atos infracionais na voz dos adolescentes em conflito com a lei. Revista Psicologia: teoria e pesquisa, Brasília, v. 24, n. 2, p. 151-159. 2008. Disponível em: http://www.scielo.br/pdf/ptp/v24n2/03.pdf. Acesso em: 4 nov. 2014.

PETRACCO, M . 0 adolescente em conflito com a lei: o que a psicanálise tem a dizer? In: CONGRESSO DA FEDERAÇÃO LATINOAM ERICANA DE PSICANÁLISE E PSICOTERAPIAS PSICANALÍTICAS, 2007, Porto Alegre. Anais [...] Porto Alegre, 2007. Disponível em: www.ufrgs.br/faced/pesquisa/nupeeevs/0\%20adolescente $\% 20 \mathrm{em} \% 20$ conflito $\% 20$ com $\% 20$ a \%20lei.pdf. Acesso em: 12 mar. 2014.

RICHARDSON, R. Pesquisa social: métodos e técnicas. 3. ed. São Paulo: Editora Atlas, 1999.

ROCHA, S. O uso de drogas pelos adolescentes autores de ato infracional na cidade de Porto Alegre: uma questão só de polícia? 2002. Monografia (Pós-Graduação em Direito Comunitário) - Fundação Escola Superior do M inistério Público, Porto Alegre, 2002. Disponível em: www.mprs.mp.br/areas/infancia/arquivos/usodrogas.pdf. Acesso em: 17 set. 2013.

SOARES, R. et al. A mensuração do estigma internalizado: revisão sistemática de literatura. Psicologia em Estudo, Maringá, v. 16, n. 4, p. 635-645, out./dez. 2011. Disponível em: http://www.scielo.br/pdf/pe/v16n4/a14v16n4.pdf. Acesso em: 22 set. 2014. 
TEJADAS, S. Juventude e ato infracional: as múltiplas determinações da reincidência. Porto Alegre: EDIPUCRS, 2007.

TOLEDO, B. Alargando as margens: um estudo sobre processos de resiliência em adolescentes em conflito com a lei. 2010. Dissertação (M estrado em Política Social) Universidade Federal do Espírito Santo, Vitória, 2010. Disponível em: http://portais4.ufes.br/posgrad/teses/tese_3826_Bruno\%20Alves\%20de\%20Souza\%20Toled o.pdf. Acesso em: 22 set. 2014. 